https://doi.org/10.48009/2_iis_2009_485-494

\title{
A COMPREHENSIVE RISK-BASED AUDITING FRAMEWORK FOR SMALL- AND MEDIUM- SIZED FINANCIAL INSTITUTIONS
}

\author{
Petter Lovaas, Dakota State University, lovaasp@ pluto.dsu.edu
}

\begin{abstract}
Information technology audits are vital information management programs for banks and financial institutions. A plethora of laws and regulations exists, requiring financial institutions to develop an information technology audit program to support its information technology infrastructure and keep non-public customer information secure. Furthermore, banks are required to complete a risk-based audit on an annual basis to comply with regulators. This research combines two previously identified frameworks, the Comprehensive Risk-Based Auditing Framework (CRBA) and Small to Medium Entity Risk Assessment Model (SMERAM), to further develop the audit process. Combining these two frameworks will create a critical component of a risk-based audit, allowing critical audit resources to focus more on essential areas and assets. Having a sound risk-based audit program will improve the overall information security posture for banks and financial institutions, and is part of critical regulatory requirements. Furthermore, this research utilizes an example to demonstrate the process, and concludes with testing of the framework.
\end{abstract}

Keywords: Risk-Based IT Auditing, Information Security, Small- and Medium-Sized Financial Institutions, Risk Assessment.

\section{INTRODUCTION}

In the Information Technology Audit Program (IT audit) Booklet, The Federal Financial Institutions Examination Council (FFIEC) states that:

A well-planned, properly structured audit program is essential to evaluate risk management practices, internal control systems, and compliance with corporate policies concerning IT-related risks at institutions of every size and complexity. Effective audit programs are riskfocused, promote sound IT controls, ensure the timely resolution of audit deficiencies, and inform the board of directors of the effectiveness of risk management practices. An effective IT audit function may also reduce the time examiners spend reviewing areas of the institution during examinations. Ideally, the audit program would consist of a full-time, continuous program of internal audit coupled with a wellplanned external auditing program [8]

Furthermore, the FFIEC IT Handbook documents that a sound, risk-based audit should include and cover the following areas:

- Identify areas of greatest IT risk exposure to the institution in order to focus audit resources;

- Promote the confidentiality, integrity, and availability of information systems;

- Determine the effectiveness of management's planning and oversight of IT activities;

- Evaluate the adequacy of operating processes and internal controls;

- Determine the adequacy of enterprise-wide compliance efforts related to IT policies and internal control procedures; and

- Require appropriate corrective action to address deficient internal controls and follow up to ensure management promptly and effectively implements the required actions. [8]

Banks and financial institutions are, according to regulations, required to develop an information technology audit program to support its information technology infrastructure, to keep non-public customer information secure, and to conduct a risk-based audit on an annual basis. This audit can be conducted either internally or externally. Whether the institution is conducting its own IT audits, or contract for it externally, the question is the same-how to complete the audit successfully. Because regulators provide little or no guidance to financial institutions, it is difficult to prepare for audits. Of the audit models on the market today, none are customized to provide feedback for both, adequacy and compliance, include the human factors of auditing, and at the same time take into consideration the riskbased auditing requirements outlined by regulators particularly aimed toward small- and medium-sized financial institutions. A framework that combines these will increase the bank's important information security posture.

The purpose of an IT audit is to discover where improvements can be made, and to ensure that the 
company is in compliance with internally and externally mandated laws and regulations. All industries should perform an IT audit, but it is critical for banks and financial institutions this is extremely critical, as regulators will examine/audit institutions every eighteen months to ensure compliance. If an institution is not compliant, the Federal Deposit and Insurance Corporation (FDIC) can shut the bank down [21].

This research will define what a risk-based audit is and will also look at some of the most prominent audit models in the market today and documenting its shortcomings as it relates to small- and medium-sized financial institutions. Furthermore, this paper will suggest a new framework to risk-based auditing and how the model can successfully be implemented in small- and medium-sized financial institutions. This research will conclude with a testing of the framework at two community banks.

\section{LITERATURE REVIEW}

For a long time control-based auditing has been the biggest player in the auditing area. Most of the frameworks commonly used today are still considered control-based. However, risk-based auditing has emerged and is designed to fill the large gaps that the standards of control based auditing have left.

The time for controls review for IT audits is in the past; today federal examiners are responsible for much more, including evaluating the importance of the information technology audit function, particularly as it relates to specific functions. A good example of this is the institution's ability to report and detect important risk factors to the board of directors as well as to senior management [18].

Risk-based IT auditing is an approach which focuses on analyzing risk applicable to the business. More precisely, "[It] is an approach that focuses on the response of the organization to the risks it faces in achieving its goals and objectives. Unlike other forms of audit, [Risk Based Auditing] starts with business objectives and their associated risks rather than the need for controls. It aims to give independent assurance that risks are being managed to an acceptable level and to facilitate improvements where necessary" [3].

FFIEC outlines in its IT Handbook that a risk-based IT audit should:

- Identify the institution's data, application and operating systems, technology, facilities, and personnel;

- Identify the business activities and processes within each of those categories;
- Include profiles of significant business units, departments, product lines, or systems, and their associated business risks and control features, resulting in a document describing the structure of risk and controls throughout the institution;

- Use a measurement or scoring system that ranks and evaluates business and control risks for significant business units, departments, and products;

- Include board or audit committee approval of risk assessments and annual risk-based audit plans that establish audit schedules, audit cycles, work program scope, and resource allocation for each area audited;

- Implement the audit plan through planning, execution, reporting, and follow-up; and

- Include a process that regularly monitors the risk assessment and updates it at least annually for all significant business units, departments, and products or systems. [8]

Risk-based internal auditing (RBIA) is considered the methodology that the internal audit department utilizes to ensure that risks are being managed and assures that the residual risk falls within appropriate levels. Basically, risk- based auditing ensures that the organization is within its acceptable level of risk after controls are put into place. The board of directors in any organization is ultimately responsible for this acceptable risk level [11].

According to Griffiths, in order for any risk-based audit framework to be implemented successfully in an organization, the board of directors and upper management must ensure that the institution has identified all risks for each asset, and through a risk assessment process, that controls have been implemented to reduce the risks for each asset, depending on its criticality level, and falls within the acceptable risk level the board has determined and approved. Ensuring a comprehensive risk management process is critical to any organization, and will define the responsibilities of management, external audit processes, internal audit, and any other functions that provide assurance [11].

What really differentiates risk-based auditing is the fact that it extends and improves the risk assessment process, looking at areas based on risk instead of focusing on controls [15]. By focusing on high risk areas, the auditor must also understand that "some activities might never be deemed important enough to receive internal audit attention" [17] because they are considered low risk areas.

A risk-based audit also requires that auditors completely understand their clients, their client's industry, the nature of their business and the environment that they operate in. "Without a thorough understanding, the auditor may fail to correctly identify the critical business process and 
corresponding internal controls that he should evaluate [13].
This relatively new audit approach is very different from the more traditional one of conducting audits. Table 1 outlines these differences.

Traditional vs. Risk-Based Audit Approach

\begin{tabular}{|l|l|}
\hline Traditional & Risk-Based \\
\hline Audit focus & Business focus \\
\hline Transaction-based & Process-based \\
\hline Financial account focus & Customer focus \\
\hline Compliance objective & Risk identification, process improvement objective \\
\hline Policies and procedures focus & Risk management focus \\
\hline Multiyear audit coverage & Continual-risk-reassessment coverage \\
\hline Policy adherence & Change facilitator \\
\hline Budgeted cost center & Accountability for performance improvement results \\
\hline $\begin{array}{l}\text { Career auditors } \\
\text { compliance }\end{array}$ & Opportunities for other management positions \\
\hline
\end{tabular}

Table 1. Traditional vs. Risk-Based Audit

\section{CURRENT FRAMEWORKS}

One of the major aspects of conducting and planning an IT compliance audit involves selecting the framework utilized. The financial sector requires very specific regulatory guidelines for conducting an information technology audit [5]. There are several standards that can be utilized to assist in complying with these standards. Even if an organization has more than one regulator to comply with, standards, such as the International Organization for Standards (ISO) 27002, will help compliance with these regulations [10]. Because guidance from regulators is scarce, audit frameworks can be utilized for more specific guidance on conducting an audit. Some of the most accredited frameworks on the market are the Committee of Sponsoring Organizations Enterprise Risk Management (COSO ERM) framework, Statements of Auditing Standards (SAS) and the Control Objectives for Information and related Technology (COBIT). Although they offer some similarities when conducting a compliance audit, none of these frameworks are identical. There are, however, some key areas that must be addressed and are a part of all of frameworks [5]:

- Board of director and senior management oversight

- Risk identification and assessment

- The Compliance organization itself

- Policies and procedures

- A system of internal controls
- Training

- Self-monitoring and remediation

- A customer complaint process

- Reporting and record keeping

- Board of directors and management reporting

As identified in previous research, most of these frameworks fall short of regulatory requirements for small- and medium- sized financial institutions [14]. The ISO 27002 standard is often referred to as "mile wide, and inch deep" [20]. The ISO standards cover many topics, but none in depth. Utilizing the COSO framework will leave the auditor to rely heavily on the reviews of policies and procedures to ensure that the audit complies with the framework. The goal of a COSO audit is to ensure that the organization and its management have in place appropriate internal controls and ensure a strategic view. The process extends through monitoring and decisions relating to financial reporting and internal control [23]. In addition, the auditor will balance the audit findings and make a final overall evaluation that outlines the level of risk in the five areas of the COSO model. Even within the model, strengths in certain elements may mitigate weaknesses in other elements [23]. Because no standard exists in auditing the soft controls, in practice utilizing the COSO framework may not be as easy as it seems [22].

There are several Statements of Auditing Standards (SAS) that have been published for auditing financial information, most of which can also be implemented in 
the IT field. "The eight new Statement of Auditing Standards (SAS No. 104 though SAS No. 111) require auditors to rigorously assess the entity's risks of material misstatement (RMM) with regard to their financial statements and understand what is being done to mitigate them" [1].

A SAS 70 Type II can also be used to complete an IT audit. It is a test of operating effectiveness over a period of six to twelve months. Because the audits take place over time, they are highly regarded on the market [7]. However, SAS 70 audits are more applicable to organizations wishing to ensure their operating effectiveness to their customers [13].

SAS 94 is yet another framework for conducting an IT audit, providing very specific guidance on testing controls put in place by the organization [6]. It can include all or some of the following six steps: Physical and Environmental Review, System Administration Review, Application Software Review, Network Security Review, Business Continuity Review, and Data Integrity Review. Furthermore, the authors state that a majority of IT audits used the SAS 94 framework [13].

The final audit framework to be discussed in this research is more often utilized by IT auditors, and is referred to as the COBIT framework. "COBIT is a comprehensive IT governance framework that has achieved international recognition and usage because it deals with every aspect of IT" [9]. The intent of information technology governance and the aim behind COBIT is to ensure that information technology and organizational needs are met and that information technology extends the organization's strategies and objectives [16].

In essence, the COSO framework is designed to provide guidance on addressing internal control needs throughout an organization, and does not necessarily directly relate back to IT. COBIT, on the other hand, is designed to be very open, and allows the organization to address specific information technology control issues.

Ultimately, all audit frameworks discussed in this section follow the IT audit Life Cycle outlined by Hunton, Bryant, and Bagranoff. It indicates that all audit frameworks include the following:
- Planning

- Risk Assessment

- Prepare Audit Program

- Gather Evidence

- Form Conclusions

- Deliver Audit Opinion

- Follow Up [13]

\section{SUMMARY OF PROBLEM}

Because no comprehensive risk-based audit framework, particularly designed for small- and medium- sized financial institutions exists, the CRBA framework has been developed. It includes vulnerability assessments, penetration testing, internal auditing, social engineering, and, finally, an external audit. Combining all of these processes ensures an innovative, ongoing audit framework designed to fully satisfy regulators and most of all the needs that small- and medium- sized financial institutions have in complying with regulatory requirements. Figure 1 shows and explains the CRBA framework [14].

"An appropriate assessment of risk is the foundation of a high quality audit" [2]. "Risk-based auditing (RBA) extends and improves the risk assessment model by shifting the audit vision. Instead of looking at the business process in a system of internal control, the internal auditor views the business process in an environment of risk" [15].

Previous research has suggested that a new innovative Risk Management Program can help with risk management for small- and medium- sized financial institutions (SMERAM) [19]. SMERAM helps determine if they are compliant with regulatory requirements and for each asset fall within the acceptable risk level that will depend on the size and complexity of the financial institution. "Each institution has its own acceptable risk level, which is derived from its legal and regulatory compliance responsibilities, its threat profile, and its business drivers and impacts" [12]. SMERAM further helps to complete a valid risk assessment that is both, an adaptive and integrated part, of the entire information security program [19]. The SMERAM process includes nine steps outlined in Table 2.

\section{SMERAM Risk Assessment Process}

\begin{tabular}{|l|l|l|}
\hline $\begin{array}{l}\text { 1. Inventory assets, vendors, and } \\
\text { service providers }\end{array}$ & $\begin{array}{l}\text { 4. Determine Inherent Risk. Which } \\
\text { assets represent risk to the bank? }\end{array}$ & $\begin{array}{l}\text { 7. Demonstrate compliance, } \\
\text { reporting, improve the process }\end{array}$ \\
\hline 2. Develop priorities, protection & 5. System Controls. What system & 8. Organizational Controls. What \\
\hline
\end{tabular}




\begin{tabular}{|l|l|l|}
\hline $\begin{array}{l}\text { profile (Confidentiality, Integrity, } \\
\text { Availability-Volume) }\end{array}$ & $\begin{array}{l}\text { safeguards does the bank want to } \\
\text { implement? }\end{array}$ & $\begin{array}{l}\text { safeguards does the bank want to } \\
\text { implement? }\end{array}$ \\
\hline $\begin{array}{l}\text { 3. Identify Threats. What are the } \\
\text { threats to each asset? }\end{array}$ & $\begin{array}{l}\text { 6. Determine Residual Risk. What } \\
\text { is the risk after applying controls? }\end{array}$ & $\begin{array}{l}\text { 9. Document Information Security } \\
\text { Program and establish an effective } \\
\text { set of IT policies }\end{array}$ \\
\hline
\end{tabular}

Table 2. SMERAM Risk Assessment Process

A comprehensive risk assessment process and information technology audit process is vital to any comprehensive information security program when considering smalland medium- sized financial institutions. "The two major pillars of the program include the IT Risk Assessment and the IT Audit. The IT Risk Assessment evaluates the use of technology to identify appropriate compensating controls, while the IT Audit evaluates the compliance and adequacy of these controls" [24].

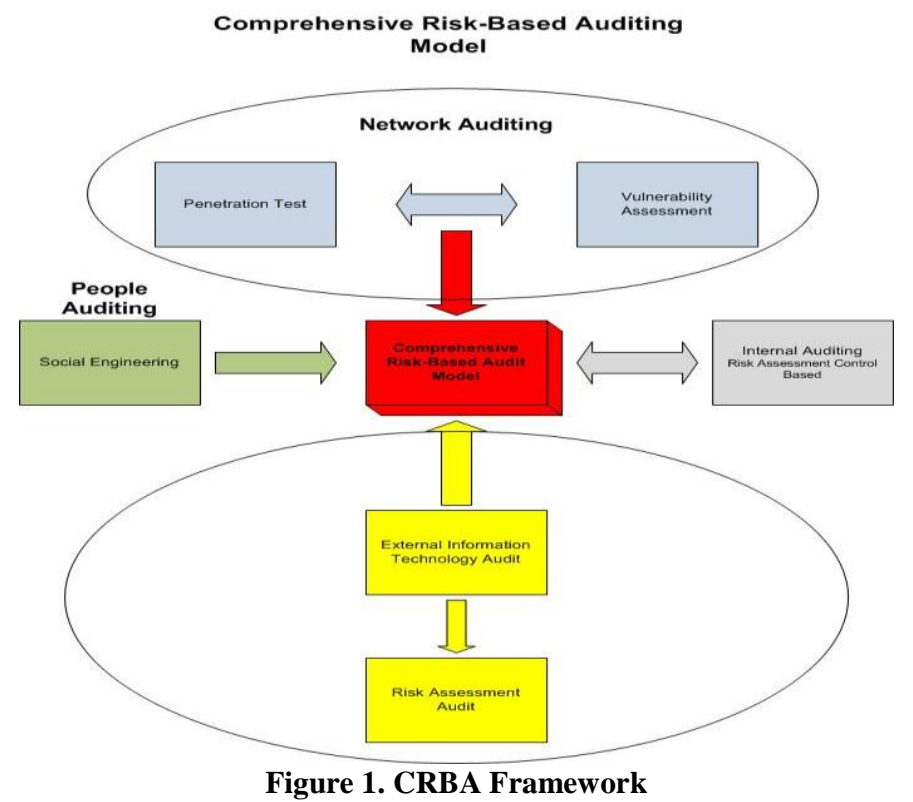

\section{SOLUTION AND MODEL}

As indicated previously, Information Technology auditing is critical to any small- and medium- sized financial institution. Furthermore, banks are required to complete a risk-based audit on an annual basis. Combining the CRBA framework with the SMERAM model will create a risk-based audit program. As indicated in Figure 2, part of the external audit process includes the risk assessment audit. Figure 2 further develops the external audit process by adding threats and controls already developed from the risk assessment for part of the on-site audit process.

Included in the Risk Assessment Audit step are several details. The initial step is to scope between 5-10 assets, selected for audit by the financial institution. An asset is considered to be anything of value to the bank, and could be physical equipment, software, or services. This number will depend on the size and complexity of the institution. These assets are considered high-risk assets within the organization. A predetermined set of controls will be added to the asset. Furthermore, all of these controls will be checked on-site. For medium- to highrated assets the process works the same, except only the predetermined critical controls will be checked during the on-site audit. Finally, no auditing will be done on lowrisk assets. 


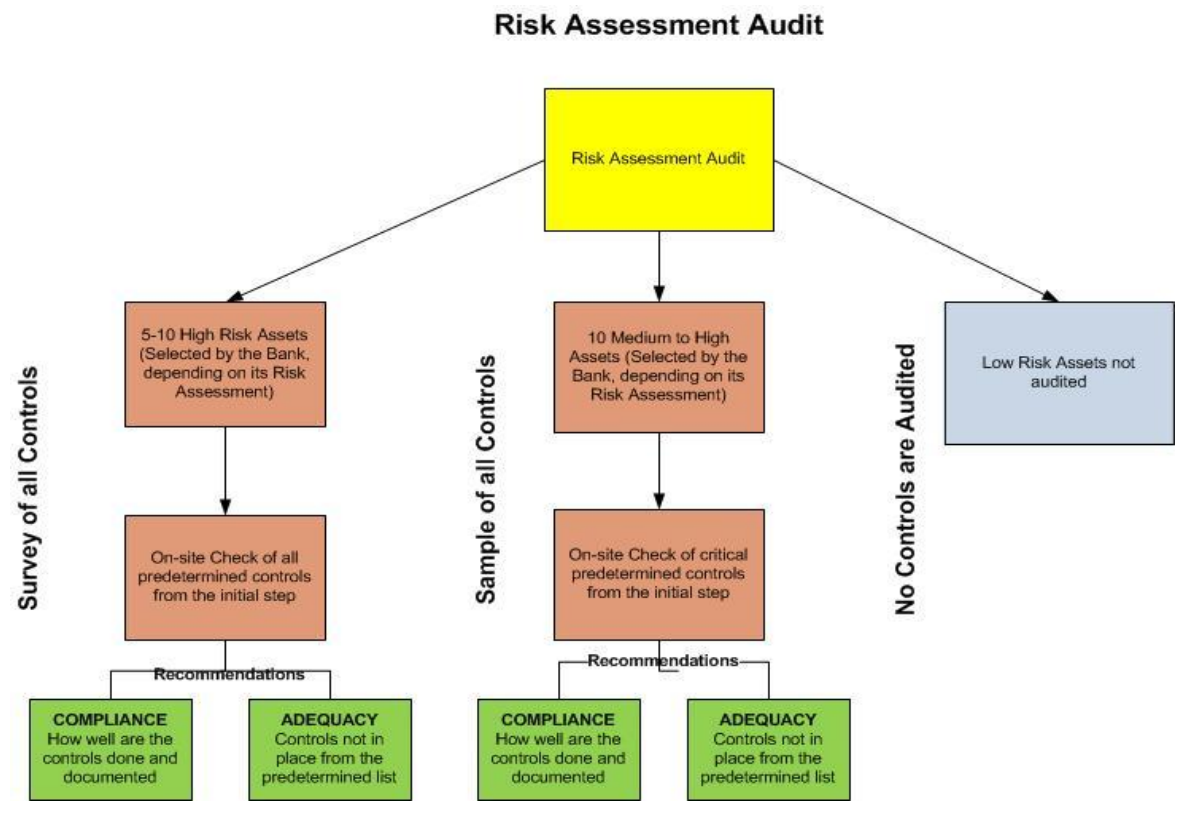

Figure 2. Risk Assessment Audit

\section{EXAMPLE}

Secure Banking Solutions LLC has developed a Risk Assessment tool based on the SMERAM Risk Assessment Process previously discussed in this paper. This research will use this process as an example for developing the audit work papers. It will look at two examples, one high- and one medium- risk asset. The reason is to illustrate the risk-based process as it relates to checking the controls. There are several other threats and controls that will also be a part of the audit, but for example purposes only data loss as a threat is considered here. Table 3 shows a list of all controls associated with each asset. They are rated high, medium, and low. Because the Core Banking System (CBS) is considered a high- risk asset for all banks, it is used in this example. The second asset, again for example purposes, is a web server. For the CBS, all controls are verified on-site, while for the web server, samples of the controls are verified.

\begin{tabular}{|c|l|c|l|}
\hline \multicolumn{1}{|c|}{ Threats and Controls for Core Banking System } & \multicolumn{2}{l|}{ Threats and Controls for Web Server } \\
\hline Threat: & & Threat: & \multicolumn{1}{c|}{ Control: } \\
\hline Data Loss & & Data Loss & \\
\hline H & Security Information and Event Management & H & Security Information and Event Management \\
\hline H & Unique User Accounts & H & Data Loss Prevention \\
\hline M & Activity Logs & H & Activity Logs \\
\hline M & Activity Log Monitoring & M-H & Activity Log Monitoring \\
\hline L & Acceptable Use Notification & L & Acceptable Use Notification \\
\hline M & Data Loss Prevention & M & Website Filtering \\
\hline
\end{tabular}

Table 3. Threat and Control Table

Once all the controls have been documented, a work paper can be developed. For the CBS, all of the controls are verified for both, compliance and adequacy. The bank is in compliance if it has implemented the controls, done it well, and has enforced it. If the bank looks at the access logs on a monthly basis, but no documentation exits to verify the monitoring, a recommendation for further documentation will be included in the audit report. For 
adequacy purposes, the controls that the bank does not have in place will be recommended in the audit report. For the web server, that in this example is considered a medium- rated asset, a sample of the controls will be audited. More emphasis will be put on the high- rated controls; however, a sample of the most important controls in the medium and low category will also be audited.

Table 4 shows an example work paper that the auditor will take on-site to document findings. It allows the auditor to document all findings while completing the onsite audit.

\section{TESTING}

The comprehensive audit model particularly focusing on the Risk Assessment process was tested and implemented in three community banks. All were asked a set of questions before and after the audit. Questions asked prior to the audit were:

1. How do you currently conduct your audit, internally or externally?

2. Do you currently conduct a Risk-Based Audit?

3. Does your audit focus more on the high-risk areas or are resources split equally between all controls?

4. How do you like your current audit? Does it provide valuable feedback to the organization?

The following questions were asked upon completion of the audit:

1. How did this audit compare to your previous audit?

2. Did regulators approve of the audit process? If so, did you get specific comments/feedback?

3 . How would you say this model compares to your old process as it relates to where audit resources are put in place?

4. Does this process add valuable feedback and recommend controls that are critical?

Answers to the questions asked before the audit were unanimous - all banks currently conducted only external audits, as the institutions did not have the manpower or the knowledge to conduct an internal audit. Answering the second question was a bit more challenging as most of the institutions were not aware of the term risk-based auditing. The researcher explained this process and it was determined that all of the institutions are currently performing some form of controls-based audit, checking all controls, not having certain focus areas. The banks did not dislike their current audit, but they all had concerns regarding the feedback and reporting that the organization received.

After the Risk-Based Audit framework was implemented, all three banks answered that the new framework focused on more critical areas, and only checking the critical controls of lower risk assets such as a printer. Furthermore, areas of physical protection of high-risk documents were included in the RBA model, where previous audits did not focus on such areas. Compliance was audited through the institutions' current controls as explained in the SMERAM process above, and thereafter compared for adequacy to a set of "best practices," particularly based on controls designed for the financial sector.

When asking the institution about regulatory requirements, the feedback was extremely positive. Examiners were impressed by the model and its process, and the fact that the controls were especially designed for banks. This is usually lacking from other audits where recommendations are very general, as the knowledge of these companies are familiar with financial auditing, but not as it relates to IT.

Finally, as the institutions became more familiar with the RBA process, they felt that the it focused on the correct areas and provided accurate and understandable feedback.

\section{CONCLUSION AND FUTURE RESEARCH}

This paper has looked at and documented requirements put forth by regulators for financial institutions as it relates to information technology auditing. The research has investigated some of the most commonly used audit models currently on the market. Furthermore, the researchers have suggested that these frameworks lack an important aspect of information security. By suggesting a new framework, CRBA, and combining this framework with the SMERAM risk management process, the research has suggested a new and innovative risk-based audit module that allows the board of directors and upper management to audit the most critical areas. Easily utilized work papers will simplify the external audit process. This research also included testing of the model in three financial institutions. A set of questions were asked before and after the audit process to get some preliminary validation results.

Further research is required to validate this new model, and the researchers intend to test this new and innovative model in more small- and medium- sized financial institutions. Testing will ensure that the process works as intended. Furthermore, this critical testing will validate the model, and if necessary, corrections can be made to the model in the future. Finally, the researchers intend to further expand the model to ensure that it is more comprehensive and includes additional regulatory requirements for small- and medium- sized financial institutions. 
Risk Assessment Audit for XYZ Bank

\begin{tabular}{|c|c|c|c|c|c|c|c|}
\hline \multicolumn{2}{|c|}{ Threats and Controls for Core Banking System } & \multirow[t]{2}{*}{ Method of Audit } & \multirow[t]{2}{*}{ Request Information } & \multirow[t]{2}{*}{ Compliance } & \multirow[t]{2}{*}{ Adequacy } & \multirow[t]{2}{*}{ Notes } & \multirow[t]{2}{*}{$\begin{array}{c}\text { Exception / } \\
\text { Recommendation }\end{array}$} \\
\hline Threat: & Control: & & & & & & \\
\hline \multicolumn{8}{|l|}{ Data Loss } \\
\hline $\mathrm{H}$ & $\begin{array}{l}\text { Security Information and } \text { Event } \\
\text { Management }\end{array}$ & Physical Check & & $\begin{array}{l}\text { The Bank has acquired } \\
\text { software (GFI Events } \\
\text { Manager) to monitor and } \\
\text { report security events on the } \\
\text { CBS. However, the software } \\
\text { has not yet been installed. }\end{array}$ & $\begin{array}{l}\text { The Bank should, in } \\
\text { a timely manner, } \\
\text { install and implement } \\
\text { the SIEM software } \\
\text { acquired. }\end{array}$ & & 1 \\
\hline $\mathrm{H}$ & Unique User Accounts & Physical Check & & $\begin{array}{l}\text { All user accounts on the CBS } \\
\text { are considered unique. They } \\
\text { consist of the first four letters } \\
\text { of last name, the two- digit } \\
\text { start month, and two- digit } \\
\text { start year. }\end{array}$ & NA & & \\
\hline M & Activity Logs & Physical Check & & & & & \\
\hline $\mathrm{M}$ & Activity Log Monitoring & Documentation & $\begin{array}{l}\text { CBS Activity Logs, and } \\
\text { documentation }\end{array}$ & $\begin{array}{l}\text { The Bank is monitoring the } \\
\text { activity logs on a needs basis. } \\
\text { No formal process or } \\
\text { documentation exists to } \\
\text { support the Banks Logging and } \\
\text { Monitoring Program. }\end{array}$ & $\begin{array}{lr}\text { The Bank } & \text { should } \\
\text { create a formal } \\
\text { process to ensure that } \\
\text { activity logs } r \text { are } \\
\text { reviewed } \\
\text { monitored on a a } \\
\text { regular basis. }\end{array}$ & & 1 \\
\hline M & Acceptable Use Notification & Physical Check & & & & & \\
\hline $\mathrm{M}$ & Data Loss Prevention & Physical Check & & & & & \\
\hline \multicolumn{8}{|c|}{ Threats and Controls for Web Server } \\
\hline Threat: & Control: & & & & & & \\
\hline \multicolumn{8}{|l|}{ Data Loss } \\
\hline $\mathrm{H}$ & $\begin{array}{lll}\text { Security Information and } \\
\text { Management }\end{array}$ & Physical Check & & & & & \\
\hline $\mathrm{H}$ & Data Loss Prevention & NA & & & & & \\
\hline $\mathrm{H}$ & Activity Logs & Physical Check & & & & & \\
\hline M-H & Activity Log Monitoring & Documentation & 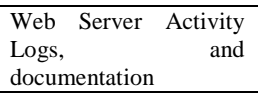 & & & & \\
\hline M & Acceptable Use Notification & NA & & & & & \\
\hline M & Website Filtering & Physical Check & & & & & \\
\hline M & Unique User Accounts & NA & & & & & \\
\hline $\mathrm{L}$ & Firewall: Egress Filtering & Physical Check & & & & & \\
\hline
\end{tabular}

Table 4. Risk Assessment Audit Work Papers 


\section{REFERENCES}

1. Anonymous (2007) Embracing IT RiskBased Auditing. CPA Technology Advisor; Oct 2007; 17, 6; 67-69

2. Accounting Web (2008). PCAOB proposes seven new risk assessment auditing standards. Retrieved April 3, 2009 from http://www.accountingweb.com/cgibin/item.cgi $\mathrm{id}=106299 \& \mathrm{~d}=883 \& \mathrm{~h}=884 \& \mathrm{f}=$ 882\&dateformat $=\% 0 \% 20 \% \mathrm{~B} \% 20 \% \mathrm{Y}$

3. Arun District Council (2009). Risk-Based Auditing. Retrieved April 29, 2009 from http://www.arun.gov.uk/cgibin/buildpage.pl?mysql=1767

4. Basilo, T. A. (2007). Reducing SarbanesOxley Compliance Costs. The CPA Journal Jan 2007; 77, 1;6-8.

5. Beaumier, Carol (2007). How to Audit Compliance in the Financial Services Industry: A Primer. Retrieved November 2008 from http://www.knowledgeleader.com/Knowled geLeader/Content.nsf/Web+Content/HIHow toAuditComplianceinFSI!OpenDocument

6. Cerullo, J.V, Cerullo M.J (2003). Impact of SAS No. 94 on Computer Audit Techniques. Retrieved January 25, 2008 from http://www.isaca.org/Template.cfm?Section $=$ Home \&CONTENTID $=16201 \&$ TEMPLAT E=/ContentManagement/ContentDisplay.cf $\mathrm{m}$

7. Denyer, Charles (2008). SAS 70 Audits in Today's IT World. Retrieved January 25, 2008 from http://it.toolbox.com/blogs/sas70audit/sas70-audits-learn-about-pricing-and-otheraudit-issues-25525

8. FFIEC, 2008. Audit Handbook. Retrieved March 15, 2008 from http://www.ffiec.gov/ffiecinfobase/booklets/ audit/audit.pdf

9. Financial Services Technology (2009). Performing COBIT Assessments. Retrieved February 1, 2009 from http://www.usfst.com/pastissue/article.asp?a $\mathrm{rt}=272028$ \&issue $=228$

10. Greene, Sari S. (2006). Security Policies and Procedures; Principles and Practices. New Jersey: Pearson.

11. Griffiths, David (2006). Risk-Based Internal Auditing: Three views on Implementation, retrieved April 1, 2009 from

http://www.internalaudit.biz/files/implement ation/Implementing\%20RBIA\%20v1.1.pdf
12. Harris, Shon (2006). How to Define an Acceptable Level of Risk. Retrieved April 21, 2009 from http://searchsecurity.techtarget.com/tip/1,28 9483,sid14_gci1177563,00.html\#

13. Hunton, J.E, Bryant, S.M, Bagranoff, N.A (2004). Core Concepts of Information Technology Auditing. New Jersey: Wiley

14. Lovaas, P., Streff K., Podhradsky, A. A Comprehensive Information Technology Audit Framework for Small- and MediumSized Financial Institutions. Hawaii International Conference on Business, June 12-15, 2009, Honolulu, Hawaii

15. McNamee, D. (1997) Risk-based Auditing. The Internal Auditor; Aug 1997; 54, 4; 22 27

16. Martin, Alyssa G. (2008). Assess Your IT Controls. Retrieved January 30, 2009 from http://www.creditunionmagazine.com/Asses s_Your_IT_Controls_823.html

17. Parkinson, M. (2004) A Strategy for Providing Assurance. The Internal Auditor; Dec 2004; 61, 6; 63-68

18. Patel, Ray (2006). Regulators Are Becoming More Focused on Information Technology Audits. Retrieved April 2, 2009 from

http://www.plantemoran.com/Industries/Fin ancialInstitutions/CreditUnions/Resources/C redit+Union+Advisor/2006+Spring+Issue/R egulators+Are+Becoming+More+Focused + on+Technology+Audits.htm

19. Podhradsky, A., Streff, K., Engebretson, P., Lovaas, P. (2009). An Innovative Information Technology Risk Assessment Model for Small and Medium-Sized Financial Institutions. Hawaii International Conference on Business, June 12-15, 2009, Honolulu, Hawaii.

20. Privacy Rights Clearinghouse (2008). A Chronology of Data Breaches. Retrieved November 10, 2008, from http://www.privacyrights.org/ar/chrondatabr eaches.htm

21. Rothman, Mike (2007). Audit: Five Fearless Strategies for Survival. Retrieved March 7, 2008 from http://searchciomidmarket.techtarget.com/tip/0,289483,sid1 83_gci1273981,00.html

22. Simmons, Mark R. (1997). COSO Based Auditing. Retrieved January 30, 2009 from http://www.cwu.edu/ atkinsom/coso.htm

23. Singleton, Tommie (2008). The COSO Model: How IT Auditors can use it to Measure the Effectiveness on Internal 
Controls (Part 2). Retrieved January 30, 2008 from http://www.isaca.org/Content/NavigationMe nu/Students_and_Educators/IT_Audit_Basic s/IT_Audit_Basics_The_COSO_Model_Ho w_IT_Auditors_Can_Use_IT_to_Measure_t he_Effectiveness_of_Internal_C.htm

24. Streff, K., Lovaas, P., Podhradsky, A. (2009). A Progressive Information Security Management Model for Small- and MediumSized Financial Institutions. Hawaii International Conference on Business, June 12-15, 2009, Honolulu, Hawaii 